\title{
Prophylactic ciprofloxacin for prostate biopsy: a losing bet?
}

\section{Maxim Bloomfield and Timothy Blackmore}

We thank Pruthi and Liss for their excellent News and Views commentary (Prophylactic antibiotic for prostate biopsy: the carbapenem gamble. Nat. Rev. Urol. 14, 394-396 (2017)) which discusses our recent paper on ertapenem prophylaxis for transrectal ultrasonography-guided prostate biopsy $(\text { TRUPB })^{1,2}$. We share their concerns regarding the generation of antimicrobial resistance - indeed, this worry was the reason for performing our study - and agree that inappropriate broad-spectrum antibiotic use should be avoided to preserve them for the future.

To add to their discussion, we find it surprising that ciprofloxacin has remained the recommended antibiotic prophylaxis for TRUPB by the American Urological Association and the European Association of Urology in the face of steadily rising fluoroquinolone resistance ${ }^{3-6}$. Evidently, generation of resistance seems to not have been of sufficient concern to result in changes to this recommendation. We are not aware of any studies analogous to ours that provide any degree of reassurance regarding the collateral damage caused by ciprofloxacin prophylaxis. Canadian guidelines recommend that antibiotic choices should be made on the basis of local data, but do not provide a clear recommendation ${ }^{7}$.

An assumption seems to be widely held, including by Pruthi and Liss, that carbapenems pose a greater risk than fluoroquinolones for the development of clinically relevant antibiotic resistance. We have demonstrated in our population that ertapenem prophylaxis does not drive carbapenem resistance, and several studies suggest that the use of fluoroquinolones poses a greater risk ${ }^{8-10}$. We acknowledge that in populations with higher levels of carbapenem resistance ertapenem prophylaxis might carry an unknown risk, but we argue that the 'ciprofloxacin gamble' is high risk, has already failed, and alternative options must be sought.
Maxim Bloomfield and Timothy Blackmore are at the Department of Infection Services, Wellington Regional Hospital, Capital and Coast District Health Board, Riddiford Street Wellington 6021, New Zealand.

Correspondence to M.B. maxim.bloomfield@ccdhb.org.nz doi:10.1038/nrurol.2017.154 Published online 4 Oct 2017

1. Pruthi, D. K. \& Liss, M. A. Prophylactic antibiotic for prostate biopsy: the carbapenem gamble. Nat. Rev. Urol. 14, 394-396 (2017).

2. Bloomfield, M. G. et al. Routine ertapenem prophylaxis for transrectal ultrasound guided prostate biopsy does not select for carbapenem resistant organisms: a prospective cohort study. J. Urol. 198 362-368 (2017).

3. Wolf, J. S. Jr et al. Best practice policy statement on urologic surgery antimicrobial prophylaxis. J. Urol. 179, 1379-1390 (2008).

4. European Association of Urology (EAU). Guidelines on urological infections [online], (2017). https://uroweb. org/guideline/urological-infections/

5. Zaytoun, O. M. et al. Emergence of fluoroquinoloneresistant Escherichia coli as cause of postprostate biopsy infection: implications for prophylaxis and treatment. Urology 77, 1035-1041 (2011).

6. Feliciano, J. et al. The incidence of fluoroquinolone resistant infections after prostate biopsy - are fluoroquinolones still effective prophylaxis? J. Urol. 179, 952-955 (2008).

7. Mrkobrada, M. et al. CUA guidelines on antibiotic prophylaxis for urologic procedures. Can. Urol. Assoc. J. 9, 13-22 (2015)

8. Kritsotakis, E. I. et al. Antibiotic use and the risk of carbapenem-resistant extended-spectrum- $\beta$ lactamase-producing Klebsiella pneumoniae infection in hospitalized patients: results of a double casecontrol study. J. Antimicrob. Chemother. 66, 1383-1391 (2011).

9. Falagas, M. E. et al. Risk factors of carbapenemresistant Klebsiella pneumoniae infections: a matched case control study. J. Antimicrob. Chemother. 60 1124-1130 (2007)

10. Gasink, L. B. et al. Risk factors and clinical impact of Klebsiella pneumoniae carbapenemase-producing K. pneumoniae. Infect. Control Hosp. Epidemiol. 30 , 1180-1185 (2009)

Competing interests statement

The authors declare no competing interests. 